\title{
The health effects of dust storms in the Southwest United States
}

\author{
Larrité Reed BS, Kenneth Nugent MD
}

\begin{abstract}
Blowing dust events are a common feature of life in West Texas and the Southwestern United States and are increasing in frequency. The composition of inhaled air varies from region to region and may include harmful particles, such as particulate matter, bacteria, fungi, and viruses. There are several types of blowing dust events that can be characterized by physical observations, including the source of dust, the direction of the wind, the density of the particulate matter, and several other physical parameters. All blowing dust events have the potential to cause adverse health effects. Inhalation of dust can cause direct respiratory effects that range from transient cough to acute fungal infection to acute respiratory failure. Asian dust storms increase all-cause and respiratory disease emergency room visits and pneumonia admissions. There is an association between meningococcal meningitis and Saharan dust storm intrusions into West Africa. Haboob (Arabic for strong wind) dust storms stir up large amounts of dust from the environment and can blow it into densely populated areas. The "haboob lung syndrome" has been reported in patients from West Texas who presented with dusty sputum, sterile cultures, and multilobar infiltrates. Some of these patients required admission to the hospital for acute respiratory failure and mechanical ventilation. Blowing dust events are a serious public health issue that can be avoided with prevention. Therefore, it is important to forecast blowing dust events and to get this information out to the public on days with an increase in particulate density. The population can benefit from these warnings by simply wearing a respirator mask on these days and by avoiding unnecessary trips outside.
\end{abstract}

Keywords: dust, wind, dust storms, disease transmission, Coccidioides immitis

The composition of inhaled air depends on multiple factors and varies from region to region. Important considerations include particulate matter (PM), biomaterials, such as bacteria, fungi, and viruses, industrial pollutants, such as ozone and nitric oxide, and inhaled metals. ${ }^{1}$ The concentration of these components is likely critical to any adverse health effects. Some parts of the world have frequent dust storms. These can be defined by a lack of visibility beyond $1 \mathrm{~km}$ or by qualitative descriptions, such as dust in suspension, blowing dust, dust storm, and severe

Corresponding author: Kenneth Nugent Contact Information: Kenneth.nugent@ttuhsc.edu DOI: $10.12746 /$ swrccc.v6i22.431 dust storms. One operational definition of a dust storm is an increase in the PM density to greater than $100 \mu \mathrm{g} / \mathrm{m}^{3}$. This information can be determined with monitors which measure PM and the size distributions based on aerodynamic diameters $\leq 2.5 \mu \mathrm{m}$ and $\leq 10 \mu \mathrm{m}$. Other important factors include the path of the dust storm, the season, the area of involvement, and the duration. In general, the density of PM is higher in Southeast Asia, and the frequency of dust storms is greater in these regions than in western countries, such as the United States.

\section{DUST IN WEST TEXAS}

West Texas has many blowing dust events each year. On any given day in the spring months of March, 
April, and May, there is a $42 \%$ chance of encountering blowing dust in the El Paso region. ${ }^{2}$ Several types of blowing dust events occur in West Texas, some more common than others. These events have several characteristics, including the originating wind direction, the ability to reduce visibility, single or multiple sources of stirred up dust, and wind velocity. ${ }^{2}$ All these factors have an important role in the impact a particular storm has on the region and its population. The most common blowing dust events in West Texas occur in the spring months and are created from winds originating in the west, often from the Albuquerque region. ${ }^{2}$ These dust events can be detected by meteorologists, but the general population might not be aware of them because it is difficult to observe the associated particulate matter with the naked eye. In West Texas, the "haboob" (Arabic for strong wind) dust storms are what many people in the region regard as a true dust event because it is obvious to any observer (Figure). The haboob dust events often present with a very dramatic increase in wind speed, visible clouds of blowing dust, and reduced visibility. ${ }^{2}$ These storms are rare, making up only about $4.3 \%$ of total blowing dust events, but are dangerous to the potential health of the inhabitants due to the reduced lead-time for forecasting and heavy concentration of particulate matter circulating in the air. ${ }^{2}$ Blowing dust events are also frequent in Lubbock, Texas. Dust frequently comes from the West and Southwest into Lubbock; this is explained, in part, by an extensive area of erodible bare soil in this region during the winter and spring. ${ }^{3}$ Wind speed and soil moisture level based on the Palmar Drought Severity Index are poor predictors of blowing dust events in this area. ${ }^{4}$

\section{RESPIRATORY HEALTH EFFECTS}

Blowing dust events can cause many problems, including acute respiratory disorders. Lin and coworkers studied the associations between PM density and Asian dust storms and emergency room visits in metropolitan Taipei. ${ }^{5}$ Asian dust storms were identified by a $\mathrm{PM}_{10}$ density greater than $100 \mu \mathrm{g} / \mathrm{m}^{3}$. They found that all-cause and respiratory disease emergency room visits increased as the $\mathrm{PM}_{10}$ concentration increased. Their results also indicated that the number of all-cause and respiratory disease emergency room visits increased as the $\mathrm{PM}_{2.5}$ concentration increased. Asian dust storms with shorter durations and smaller size (i.e., less affected geographical areas) also increased allcause and respiratory disease emergency room visits. Asian dust storms were particularly important in the winter season. The highest relative risk occurred during the 2005-2008 period at $\mathrm{PM}_{10}$ densities $>50 \mu \mathrm{g} / \mathrm{m}^{3}$ compared to a reference density of $10 \mu \mathrm{g} / \mathrm{m}^{3}$. This risk (1.46; $95 \%$ confidence interval: $1.21,1.75)$ occurred in mathematical models that included Asian dust storms and did not include Asian dust storms. Kang et al studied the association between Asian dust storms and pneumonia hospitalizations in Taipei. ${ }^{6}$ They found a significant increase in the mean number of pneumonia admissions on Asian dust storm event days and post-Asian dust storm event days when compared to non-Asian dust storm event days. These results were adjusted for ambient temperature, $\mathrm{SO}_{2}$ concentrations, $\mathrm{CO}$ concentrations, and $\mathrm{O}_{3}$ concentrations. The mean number of daily pneumonia admissions increased from 279 on non-dust storm days to 314 on day 3 post dust storm. The density of $\mathrm{PM}_{10}\left(121.7 \mu \mathrm{g} / \mathrm{m}^{3}\right)$ during Asian dust storm days was approximately 2-3 times the $\mathrm{PM}_{10}$ density during non-Asian dust storm events (49.2 $\mu \mathrm{g} /$ $\mathrm{m}^{3}$ ). Merrifield et al studied emergency department visits and hospital admissions following an extraordinary dust storm in September 2009 in Sydney, Australia. ${ }^{7}$ This storm had a peak $\mathrm{PM}_{10}$ density of approximately $11,000 \mu \mathrm{g} / \mathrm{m}^{3}$. There was a significant increase in the number of asthma emergency center visits, all-cause visits, and respiratory disorder visits. This was particularly true in patients $\geq 65$ years old and patients $\leq 5$ years old. There was no change in a number of hospital admissions.

Lanzinger et al studied the association between ultrafine particles (20-100 nm) and ultrafine particle counts (in number $/ \mathrm{cm}^{3}$ ) on hospital admissions in five cities in Central and Eastern Europe. ${ }^{8}$ This study demonstrated there was a delayed and prolonged effect of ultrafine particle exposure on respiratory hospital admissions in these cities. They also found that cardiovascular and respiratory hospital admissions increased with an increase in $\mathrm{PM}_{2.5}$ density. Weichenthal et al studied the oxidative burden associated with $\mathrm{PM}_{2.5}$ and emergency center visits 


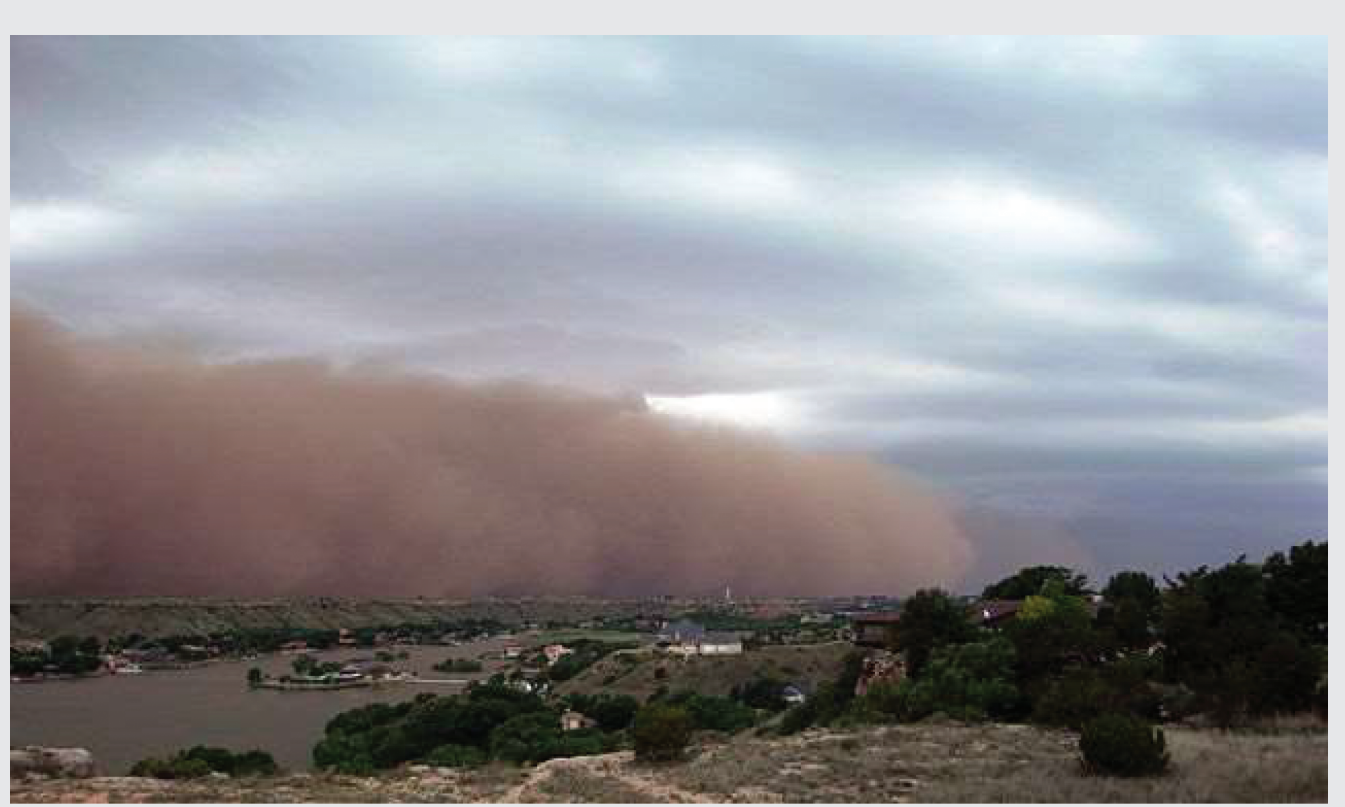

Figure. Dust storm in West Texas

for respiratory illness in Ontario, Canada, between 2004 and $2011 .{ }^{9}$ The mean 3 day PM concentrations were consistently associated with emergency room visits for all respiratory diagnoses. This was particularly true for children less than 9 years of age who had asthma. The level of glutathione related oxidative potential modified the impact of these small particles but only if the particles were in low concentrations $\left(<10 \mu \mathrm{g} / \mathrm{m}^{3}\right)$. These two studies indicate that ultrafine particles can have an impact on respiratory health and that particles with oxidative potential can increase the risk for emergency center visits for respiratory symptoms. These two studies demonstrate that any analysis of associations between the environment and health will be very complex and confounded by many unknowns.

Dust storms can carry biomaterials, including bacteria, viruses, and fungi, especially Coccidioides immitis in North America. There is an association between coccidioidomycosis and dust storms in southern Arizona, California, southwestern New Mexico, and West Texas. ${ }^{10}$ This fungus grows in the desert soil; under dry conditions its spores break free during wind gusts and are carried, suspended in air, for long periods of time.$^{10}$ Recent climate changes during the last twenty years with increased wind speeds and less rain, often in the winter months, have increased the number of patients presenting with Coccidioides infection after the inhalation of dust. There have been well documented annual outbreaks of patients presenting with Coccidioides infections following natural disasters which stir up dust and transfer spores. ${ }^{11}$ Currently, less than $50 \%$ of cases seek medical attention because they have a subclinical illness; the incidence in clinical disease often increases with more dust exposure. ${ }^{10}$ The most common presentations are chest pain, cough, and fever. ${ }^{10}$ There is also an association between meningococcal meningitis and Saharan dust storm intrusions into West Africa. This might be explained by extremely dry air causing damage to the pharyngeal mucosa which increases the opportunity for bacterial invasion. There is no information supporting this association in North America. Prolonged dust exposure can also lead to conjunctivitis and dermatologic disorders. 
Dust storms occur frequently in the spring and late fall in West Texas. These storms have the potential to cause acute exacerbations of asthma and chronic obstructive pulmonary disease. In addition, they may just increase respiratory symptoms from nonspecific irritative effects and increase healthcare utilization, including emergency center visits. Some patients exposed to intense dust storms have developed acute respiratory failure requiring mechanical ventilation. ${ }^{12}$ A study published in 2013 by Panikkath reported four cases of multilobar lung infiltrates secondary to exposure to a recent dust storm. These patients all presented 2-3 days after a haboob storm with cough; they also had "dusty" sputum, severe shortness of breath, and hypoxemia. Two patients required mechanical ventilation, and one patient died. ${ }^{12}$ The patients had negative sputum and blood cultures for bacteria and fungi. The pathogenesis of these acute respiratory disorders is uncertain. These cases may reflect overwhelming particulate exposure resulting in sterile inflammation in the alveolar spaces. These cases were called the "the haboob lung syndrome"; this study demonstrates the potential morbidity and mortality these events can have in regions where haboobs are common.

Crooks et al recently studied the association between dust storms and county level non-accidental mortality in United States between 1993 and 2005. ${ }^{13}$ Information on dust storm activities was obtained from the US National Weather Service storm database. County level mortality data were obtained from the National Center for Health Statistics; mortality rates associated with dust storms were compared to nondust storm reference days. The total non-accidental mortality rate increased by $7.4 \%$ modelled with a twoday lag period and by $6.7 \%$ modelled with a three-day lag period. The average mortality increased by $2.7 \%$ over a lag period of 0-5 days compared to non-dust storm days. There was significant associations with between dust storms and cardiovascular mortality in United States and in Arizona. There was not an association between dust storms and respiratory mortality; this result may be explained by the small number of cases of respiratory mortality. ${ }^{13}$

\section{Conclusions}

Encountering a dust-blowing event in West Texas and the Southwest United States is unfortunately common, and these particular storms are increasing in frequency. Inhalation of dust can cause direct health effects, which range from transient cough to acute fungal infection to acute respiratory failure. Coccidioides immitis is a fungus found in the soil; clinical infections have a strong association with blowing dust events in the Southwestern United States. Blowing dust events can cause significant morbidity and mortality in the general population causing acute respiratory failure and exacerbations of chronic respiratory diseases, such as asthma and COPD.

The potential health effects of these events can be deadly and cost millions of dollars in health care spending. Weather forecasting and public education can reduce the frequency of health hazards associated with dust storms. The key to protecting the population from the dangers of these events is prevention, and avoiding high concentrations of dust is essential. Simple masks can reduce particle deposition.

Article citation: Reed L, Nugent K. The health effects of dust storms in the Southwest United States. The Southwest Respiratory and Critical Care Chronicles 2018;6(22):42-46.

From: Department of Internal Medicine, Texas Tech University Health Sciences Center, Lubbock, TX

Submitted: 10/23/2017

Accepted: 11/18/2017

Reviewer: Jeff Lee PhD

Conflicts of interest: none

\section{REFERENCES}

1. Goudie AS. Desert dust and human health disorders. Environ Int 2014;63:101-13.

2. Novlan, D.J, Hardiman M, Gill T. A synoptic climatology of blowing dust events in El Paso, Texas from 1932-2005. https://ams.confex.com/ams/87ANNUAL/techprogram/ paper_115842.htm. Accessed 10/1/2017. 
3. Lee JF, Allen BL, Peterson RE, Gregory JM, Moffett KE. Environmental controls on morning dust direction in Lubbock, Texas, USA. Earth Surface Processes and Landforms 1994;19:437-449.

4. Lee JF, Wigner KA, Gregory JM. Drought, wind, and blowing dust on the southern high plains of the United States. Physical Geography 1993;14:56-67.

5. Lin YK, Chen CF, Yeh HC, Wang YC. Emergency room visits associated with particulate concentration and Asian dust storms in metropolitan Taipei. J Expo Sci Environ Epidemiol 2016;26:189-96.

6. Kang JH, Keller JJ, Chen CS, Lin HC. Asian dust storm events are associated with an acute increase in pneumonia hospitalization. Ann Epidemiol 2012;22:257-63.

7. Merrifield A, Schindeler S, Jalaludin B, Smith W. Health effects of the September 2009 dust storm in Sydney, Australia: did emergency department visits and hospital admissions increase? Environ Health 2013;12:32.

8. Lanzinger S, Schneider A, Breitner S, et al. Ultrafine and fine particles and hospital admissions in Central Europe. results from the UFIREG Study. Am J Respir Crit Care Med 2016;194:1233-41.

9. Weichenthal SA, Lavigne E, Evans GJ, Godri Pollitt KJ, Burnett RT. Fine particulate matter and emergency room visits for respiratory illness. effect modification by oxidative potential. Am J Respir Crit Care Med 2016;194: 577-86.

10. Saubolle MA, McKellar PP, Sussland D. Epidemiologic, clinical, and diagnostic aspects of coccidioidomycosis. J Clin Microbiol 2007;45:26.

11. Griffin, D. Atmospheric movement of microorganisms in clouds of desert dust and implications for human health. Clinical Microbiology Reviews, July 2007, P. 459-477.

12. Panikkath $R$, Jumper CA, Mulkey Z. Multilobar lung infiltrates after exposure to dust storm: the Haboob Lung Syndrome. Am J Med 2013;126:e5-7.

13. Crooks JL, Casio WE, Percy MS, Reyes J, Neas LM, Hilborn ED. The association between dust storms and daily nonaccidental mortality in the United States, 1993-2005. Environmental Health Perspectives 2016;124:1735-1743. 